\title{
Success Factors of Internet-Activism in Social Networks
}

\author{
Alexander Sokolov, Catherine Olenitskaya, and Yuri Golovin \\ Demidov Yaroslavl State University, Yaroslavl, Russia
}

\begin{abstract}
Social networks are gradually becoming a space for organizing and conducting civil campaigns. Authors analyze the factors that contribute to the organization of a successful campaign in social networks. They identify social groups that are most susceptible to influence in social networks. The authors also formulate a methodology for assessing the involvement of citizens in a civil campaign in social networks. The paper provides the results of a survey of experts to evaluate the factors that enable to ensure the success of the civil campaign on the Internet.
\end{abstract}

\section{Introduction}

The Internet space in the world and in Russia is characterized by general trends: an increase in the number of social networks users, which in our country are also the most viewed Internet sites; growth of messengers - programs popularity for fast messaging between an unlimited numbers of users. The role of visuality in the information dissemination are also increasing (this proves the increasing number of illustrated content in social media, as well as the Instagram audience growth).

With the Internet development, social networks become an integral part of public communication, which is formed both around individual individuals and around groups. Internet activists in different countries in order to achieve socially important tasks actively use social networks. This trend even led to the fact that the authorities should legislatively examine the Internet activists' ideas, which collected a certain number of electronic signatures depending on the scope of the task being solved. This means that digital activism can now not only influence the situation, forming public opinion, but also has a real tool for achieving the goal. Moreover, social networks are not only a means of communication and obtaining some information for users, but also serve for its creation and dissemination. Such a means of achieving any socially important goals cannot remain unclaimed by political actors. However, the Internet campaigns' organizers must take into account a number of factors, both external and internal, to achieve the necessary results.

\section{Research problem}

In this regard, the purpose of the article is to identify the factors that enable to ensure the success of the civil campaign on the Internet.

The following research hypothesis was formulated:
Civil Internet campaigns in social networks in modern Russia is not yet perceived as an independent set of actions and they are largely oriented towards an off-line campaign. It is necessary to ensure the virality of the placed material into social networks to obtain the greatest involvement of Internet users in the actions on the Internet. The success of Internet campaign in social networks largely depends on a number of factors that can be divided into "environmental factors," "content factors" and "organizational factors". At the same time, social groups have different readiness to get involved in civil campaigns on the Internet in social networks.

The authors identified and substantiated the key factors that ensure the desired result of civil campaigns in social networks on the Internet. These factors were evaluated during the field study.

The main method of data collecting was a survey of experts (conducted in May, 2016). The study involved 19 experts from specialized groups: media employees, academics, leaders of political parties and NGOs, employees of relevant government bodies, political technologists.

The analysis of communities in social networks through the "Popsters" program was also conducted. In the course of the study, the posts that caused the greatest reaction from the members of the respective communities in social networks were identified.

\section{$3 \quad$ Theory and methodology}

With the development of Internet technologies in the field of civic activism, the notion of Internet (or digital) activism appeared. Experts of the research group "Digital Activism" (Digital Activism Research Project), F. Edward, F. Howard and M. Joyce, define Internet activism as "organized public efforts to meet collective demands by government bodies in which civil campaigners and their supporters use digital mass media" [4]. Researchers also highlight a number of the Internet activism campaign's key characteristics:

\footnotetext{
*Corresponding author: klyuyev@yandex.ru
} 
1. organizers or parties should use at least one media tool;

2. it is an organized social effort that seeks to involve citizens in the campaign as participants;

3 . it is collective, which means, its goals should be determined by a group of citizens and implemented in their interests;

4. it has clear requirements that would enable it to determine whether the campaign is successful or unsuccessful;

5. it is targeted;

6. it is a public one, so, a group of initiators should not be representatives of the government or a private company.

One of the most controversial issues in the study of Internet activism is the question of the Internet slactivism role (from the English "slacker" (slacker) and "activism" (activism)). Canadian journalist M. Gladwell argues "real social changes are impossible through social media, since the links in them are fragile and decentralized, uncontrollable, whereas in order to achieve their demands, protesters need a cohesive, disciplined well-organized core with central administration" [14]. However, recent research shows that Internet users, which only display online activity and never participate in "live" events, play a big role in organizing different campaigns. Their main contribution is the information dissemination to the public and expanding the potential audience of communications until the moment when the information becomes visible to journalists.

A team of experts from Oxford, New York Universities and the University of Pennsylvania has proved that even those users who participate in the campaign, only by pressing the "repost" button, play a big role in Internet activity [1]. The experts managed to prove that peripheral players played a decisive role in increasing the coverage of protest messages and generating online content. Despite the evidence that the heart of the social movements are minorities, the success of the campaign depends more on the critical periphery activation.

One of the most important opportunities that social networks provide to activists is communication building, rapid organization and protest actions coordination. Networks allow activists to more effectively accumulate and use available resources. This feature is reflected in the theory of resource mobilization, which views social movements as collective subjects that seek to optimize the accumulation and use of material and non-material resources to achieve the goals of collective action [13].

Digital technologies provide activists with resources that were previously formed only on immediate social movements (as was the case with the Human Rights Movement in the United States in the 1960s) [15].

Internet activists' communication is connected with a number of problems:

1. New multimedia applications can facilitate the mobilization of new activists in public movements through more simple information exchange, thereby strengthening these movements. However, as mentioned above, they are not the most effective mobilization technologies and far from always show effectiveness [3].

2. Newly recruited activists of movements differ in their attitudes from those previously involved. They lack the involvement of formal and non-formal links within the move- ment, which are seen as the goal and mechanism for mobilization to participate in it. Previously involved members of the movement are key actors for involving new members [19].

3. A significant publicity of the event and coordinated actions to inform about it are needed to attract new activists who are not involved in the social movement and who do not have connections with its activists [5].

4. Collective identity formation also plays a significant role in the process of mobilization. It is understood as a sense of attachment to a group that takes collective action on a common topical issue [21]. Collective identity is connected with socialization in an organizational environment in which Internet tools only complement it [3]. In addition, there is an assumption that identity is formed only within the used Internet tools contact list [11].

5. Internet communication has a problem of trust, when "trust is inversely proportional to the degree of communication openness [15]. It can be solved with the help of selectivity when forming a group of participants, as well as personalizing their activity in a collective action [7].

Experts studying the mechanisms of impact on the audience through social media are arguing about whether social networks can be equally effective and the only ones that can be used in organizing long-term campaigns (such as electoral ones) or protest actions, and come to the conclusion that they do not.

For example, M. Gladwell in the article "Little Changes. Why the revolution will not be tweeted" [8] concludes that online campaigns can not lead to really meaningful, largescale social and political changes that require active action from participants and their readiness to take high risks, including loss of work, housing and even life.

Z. Tufekci believes that a live, non-Internet communication is needed for real change, by comparing those protests in Greensboro with the election campaign of the one Turkish leaders [20].

The argument of both experts is based on the fact that real changes in the social or political spheres are based only on real actions, and social media can either simply help in organizing or informing about the possibilities of such changes, or even reduce the campaign to the lack of result. Thus, Internet users, in online activity, consider their "public debt" to be fulfilled and do not seek to exit offline.

Nevertheless, both acknowledge that, the same campaigns can be recognized as effective ones that were organized with the help of social media. They use examples of a world bone marrow donors database creation and delivery of humanitarian aid in the context of military operations during the revolution in Egypt, as well as coverage of Turkey protests in 2013. Moreover, the last one operates in conditions of complete silence about the protests by official media that broadcast documentary films about penguins during the actions and received the nicknames "the penguin media".

The success of social and political campaigns depends on many factors that determine the degree of goal achievement at different stages of its implementation. Obviously, a campaign that has achieved the goal is successful, but campaigns organized with the help of Internet resources often do not have one goal. The purpose of the Internet campaign 
is to involve users in solving a particular problem or informing them about the existence of such a problem. However, events that precede or resolve a problem situation always occur outside the Internet field.

Nevertheless, the success of a campaign conducted with the help of modern technologies largely depends on a number of factors that can be divided into "environmental factors", "content factors" and "organizational factors".

Environmental factors include the level of social networks penetration, the degree of media technology development, the state of the political conjuncture, the level of mass media development, the state of the political culture of society, the public request to solve a specific problem.

Content factors include: virality ("emotionality") of information, visuality.

Organizational factors consist of speakers' authority, group of initiators cohesion and the organization of their actions, availability of the necessary resources for the campaign.

Let us dwell on the each factors description separately.

The level of social networks and Internet penetration has an obvious effect on the Internet activism development. At the same time, the role is played not only by the opportunities for users to access the Web and their degree of social media use, but also the intensity and depth of Internet use.

The level of mass media development and, above all, the independent media availability can have a significant impact on public and political activity. Mass media not only serve as a conductor between the Internet audience and political actors, but also in themselves significantly expand the potential audience, and also give it weight and "solidity."

The level of mass media technology development, as well as the level of Internet penetration, is an important technological factor determining the success of the campaign. For example, in remote areas where there is no connection to the Internet, it is impossible to quickly cover events; and communication between activists can also be complicated. Nevertheless, residents of district centers, where the level of Internet penetration is sufficient to involve the population in solving public and political issues, but have lack of independent media due to far distances, have the opportunity to influence the political environment.

The political culture condition of the society determines its readiness to initiate and support socially and politically significant changes. The society's political culture includes the citizens' interest in politics. According to the Public Opinion Foundation, which conducted the relevant survey in May 2016, "today significantly more often than 4-5 years ago, Russians report that they are discussing political events with people around them (growth by 13 point). As a rule, these topics are discussed with relatives $(45 \%)$, less often with friends (33\%) and colleagues (22\%)" [9].

Virality (the presence of a strong emotional component in the information) is one of the key factors that determine the information dissemination and, as a consequence, the success of the whole campaign. In the article "Deep feelings. A massive cross-lingual study on the relationship between emotions and virality"[6] the researchers of M. Gerini and J. Stoyano examine the relationship between virality and various emotions. Similar studies were conducted earlier: for example, the social network Facebook con- ducted a large-scale experiment, which showed that "emotional conditions can be transferred to other people who, being "infected" by these emotions, can experience them without realizing that they are experiencing them. Moreover, with a lack of "infected" emotions in the news line (the researchers specifically filtered their content), users started generating such content on their own: "when the positive content was getting smaller, users themselves started to write fewer positive posts and more negative ones; when there was less negative content, the opposite happened." Experts also analyzed Google+ users posts and found out that the probability of repost is higher if the information causes anger, while the "sadness" emotion reduces it. The same thesis confirmed the study of the Chinese social network Weibo [10]. Gerini and Stoyano argue that emotions such as "inspiration" (inspired), and "angry" have the greatest influence on the virality of information, while "sadness" (sad) has a lower influence.

Visuality is the second factor that determines the information distribution in social networks: users are most actively sharing content with visualization elements. Thus, the analysis of messages from numerous communities of Vkontakte, Odnoklassniki and Facebook, carried out within the framework of this research with the help of the content analysis system for social networks Popsters, shows that the most common materials are illustrations (photos, demotivators). For example, for the analyzed period (30 days, from 23.07.2015 to 21.08.2015), the picture for the two largest communities Vkontakte (with an audience of 6.86 and 7.99 million users) is as follows: the two most widely distributed messages 17741 and 26923 reposts were images. Video materials "lag" behind them several times - the most popular of them were shared only 2740 and 6015 times. This is probably due to the fact that users of social networks tend to get as much information as possible in a shorter period of time, and it is obvious that understanding and assessing photo information can be much faster than video. As for the text messages distribution that do not contain visualization elements at all, the most popular ones in the analyzed communities were shared only seven and 11 times. This pattern is typical not only for the social network "Vkontakte", where the main audience $-69.9 \%$ - are young adults under 34 years old. A similar result is provided by the analysis of the largest community in "Odnoklassniki" with an audience of 5.5 million users: the most popular message was a photo post with the number of reposts at 8564 times; video message is shared only 1258 times. Politian also understand the need for information visualization. Thus, the Russian Prime Minister Dmitry Medvedev's and opposition leader A. Navalny's Facebook pages do not have any clean text messages, not accompanied by any visualization elements. At the same time, one can observe a common pattern for all: graphics are distributed better than video (6663 repost received the most popular photo post by A. Navalny in august against 1072 video repost; 731 repost received the most popular photo post by D. Medvedev against 105 most topend video reposts).

The speakers' authority, according to experts, plays an equivalent role with virality in the campaign success. In the socio-political sphere, representatives of public organizations (including volunteer movements, charitable founda- 
tions), political parties, and the media often enjoy such authority. The influence of the latter is greatly enhanced by the media effects that they can obtain by publishing information simultaneously in social and traditional media. The social media speakers' authority is formed due to several indicators: audience coverage, audience involvement, communication and frequency of the author's publications in the media.

The cohesion of the organizers group and the organization of their actions is one of the decisive factors when it comes to large public or political campaigns. For example, the primaries of the Democratic coalition, in which PARNAS candidates participated, despite the simplicity of Internet voting, ended, according to the media, "catastrophically". "Instead of the 100,000 who wanted to vote for the preliminary elections, only 24,000 voters registered". Political scientists believe that the conflict within the coalition was the reason for such low voter turnout with the high candidates' recognition and authority on the Web [12].

The availability of the necessary resources for the campaigners determines the range of their capabilities. Such resources can be financial, organizational, personnel and technological.

Technological resources are understood as the availability of tools for analyzing data, searching for a targeted audience, as well as the ownership of these tools by the organizers. Such tools are particularly important and necessary in the large-scale campaigns organization (federal or global level).

The questions of the processes analysis occurring in the Network are being updated with the growing role of the Internet in political and social processes. Given the huge amount of information transmitted through Internet resources and limited human capabilities in the data analysis, it is necessary to use professional information processing systems. Automatic collection and processing of large information amounts from social media are produced by such systems as "Medialogy", "BrandAnalytics", "Integrum", "Semantic archive", Wobot. The principle of their work is similar: information collection about monitoring objects for a certain period and processing received information on a number of indicators: messages' audience, audience involvement (the indicator calculated from the number of likes, reposts and comments to the message). Information requests are the most interesting subject for political-researchers. For example, the analysis of the Russian Internet community's reaction to the murder of Boris Nemtsov is interesting. In the first days after the first report publication on the murder, more than 429,472 messages were published on the Net, and the total audience of these messages was 197.5 million people, with more than 350980 active users.

For example, the analysis of the oppositionist Aleksey Navalny's messages page on Facebook allows you to see that for the period January 2015-May 2016 the most number of likes was collected by the post-infographics "How much the heads of state corporations earn" - 9055. The same message is the most spread - 3010 time. The largest number of comments - 818 - gathered the opinion of Navalny about the video "The boy sings about Putin! ..". In total, since the beginning of the year, the total number of the politician's messages likes was 545,228, reposts - 91,743, comments 37,511 , and their primary audience $-214,761$ users. During the analyzed period, the share of community members exhibiting activity in the publications of the politician is $2.8813 \%$. Thus, it can be concluded that the audience of $\mathrm{Na}$ valny prefers to evaluate the messages of the politician rather than to share them or comment on them [16]. Analytics of this kind is necessary for all political actors to understand the audience preferences and build effective communication.

Financial resources are needed mainly to pay for targeted advertising, professional blogging services, as well as hiring professional SMM teams dealing with Online Reputation Management. The services of such specialists are largely needed for the image campaigns of political leaders or brands. The head of the Sidorin's Lab reputation management agency, N. Prokhorov, estimates the monthly budget of such campaigns at 175 thousand rubles [18].

Organizational resources determine the ability of political actors to create a system of unified communication between campaign participants, as well as their mobilization. Such resources can be both full and part-time. Full-time implying the willingness of participants to organize a campaign outside the Internet space (creating and distributing leaflets, appeals to the media, collecting signatures, transferring funds, intangible physical assistance, and participating in protest actions. Part-time means when participants support online a set of unified actions, including information dissemination, support for each other and their personal Internet environment involvement in the campaign.

Human resources in Internet activism are understood not only as professional, permanent team that achieves this goal, but also as the possibility of attracting influential speakers - bloggers with their own wide reach of the audience or authors whose messages are relayed from social media to the traditional media. In some cases, both persons can take place: directly influencing the adoption of political decisions, as well as activists with a high "civilian" weight.

\section{Data description and analysis}

The key issue in this study is the Internet campaigns independence degree. The majority of respondents $-43.75 \%$ expressed the opinion that "a campaign in social networks can not be considered as independent way of achieving a political goal." Experts expressed different reasons for that: Internet instrumental and technological capabilities; limited possibilities for political activism; low level of Internet freedom. However, the main reason for the low Internet campaigns independence is the lack of connection between online activism and voters' activity.

Nevertheless, a quarter of the interviewed experts agreed that in some cases, a social networks campaign can be considered as independent way to achieve the goal (mostly if this is an information goal) and see the prospects for the development of this thesis with the technologies spread, including directly related to the electoral processes.

$18.75 \%$ of experts believe that a social networks campaign can be now perceived as a self-sufficient way to achieve a political goal due to the easy use of tools, cheapness, and communication opportunities. 
As part of this study, we asked the interviewed experts to assess the factors that predetermine an Internet social media campaign success (on the previously stated indicators). Experts believe that the most significant factors are the virality of information (10), the speakers' authority (10) and the level of social networks penetration (7). Nevertheless, one of the experts believes that "everything affects, but to varying degrees ... the most important is the quality of the content" (Table 1).

Table 1. Rating of the most significant factors affecting the effectiveness of public and political campaigns (based on the results of an expert survey).

\begin{tabular}{|c|c|}
\hline Group factors / Factors & Number \\
\hline \multicolumn{2}{|l|}{ Environmental factors } \\
\hline The level of social networks penetration & 7 \\
\hline The state of the political culture of society & 5 \\
\hline The public request to solve a specific problem & 5 \\
\hline The state of the political conjuncture & 3 \\
\hline Degree of media technology development & 1 \\
\hline Level of mass media development & 1 \\
\hline \multicolumn{2}{|l|}{ Content factors } \\
\hline Virality ("emotionality") of information & 10 \\
\hline Visualization & 4 \\
\hline \multicolumn{2}{|l|}{ Organizational factors } \\
\hline Speakers' Authority & 10 \\
\hline Group of initiators cohesion and the organization of their actions & 5 \\
\hline Availability of the necessary resources for the campaign & 3 \\
\hline
\end{tabular}

The survey conducted in this study shows that personnel give the maximum value of all available resources (three experts gave them a maximum score of "10", in addition, this resource by seven points was estimated by seven experts). Equally significant are financial and organizational resources (two maximum ratings), whereas technological resources received a majority of experts' votes only at around eight points. Nevertheless, the organizational and technological resources (14 answers above the "5" mark) have an overall higher importance than the average; less, but insignificantly important - financial and human resources (12 replies above the "5" mark).

Experts did not agree on whether it is necessary to take into account social and demographic factors when conducting Internet campaigns, which set the organizers a dilemma on the target audience impact.

Media Specialist Joanna Blackley, believes that social media erases gender differences. In Ted Talks, "Social media and the end of gender," [2] the expert puts forward the idea that, despite the fact that people in social networks are the same ones who were the target audience for politicians and marketers, they now avoid including themselves in some "demographic boxes" and framework. It is now more difficult for researchers and actors to understand person's gender, age, income, but they receive much more information, exploring what users like and what interests them.

In social media, people stop forming groups by gender, age or income. They begin to group around interests and values, and these indicators are stronger than demographic categories. Marketers, searching for the target audience not by gender-age characteristics, but by thematic communities, use these features.

Experts, interviewed in this study, believe that socio-demographic factors influence the social media exposure.

Thus, the results of the survey show that the most gender-sensitive is the female audience. Nevertheless, an equal number of experts believe that men and women are equally affected by the Internet (Table 2).

Table 2. E

valuation of the audience's exposure to the social media impact on gender.

\begin{tabular}{|c|c|}
\hline Gender & Number \\
\hline Mostly women & 5 \\
\hline Men and women equally & 5 \\
\hline Mostly men & 2 \\
\hline
\end{tabular}

The youngest people aged 18-29 are the most influenced by age audience (Table 3 ). The most Internet affected by the social status, according to experts, are university and college students, non-employed intellectuals, housewives and unemployed (Table 4). 
Table 3. Evaluation of the audience's exposure to the impact of social media on the age basis.

\begin{tabular}{|c|c|}
\hline Age & Number \\
\hline $18-29$ years old & 11 \\
\hline $30-39$ years old & 5 \\
\hline $40-49$ years old & 1 \\
\hline $50-59$ years & 1 \\
\hline 60 years and over & 0 \\
\hline All equally & \\
\hline
\end{tabular}

Table 4. Evaluation of the audience's exposure to the impact of social media, depending on social status.

\begin{tabular}{|c|c|}
\hline Social status & Number \\
\hline $\begin{array}{c}\text { Students of universities and colleges } \\
\text { An intellectual who is not engaged in production (teacher, } \\
\text { doctor, journalist, etc.) }\end{array}$ & 6 \\
\hline Housewives & 6 \\
\hline Unemployed & 5 \\
\hline Workers in industrial enterprises & 3 \\
\hline Private entrepreneurs & 2 \\
\hline $\begin{array}{c}\text { Employees (employee of the enterprise apparatus, institution, } \\
\text { government bodies) }\end{array}$ & 2 \\
\hline Engineering staff & 1 \\
\hline Employees of law enforcement agencies and servicemen & 1 \\
\hline Pensioners & 1 \\
\hline All equally & 0 \\
\hline & \\
\hline
\end{tabular}

This data correlate with data on the protest activity socio-demographic aspects in Russia. For example, in the article "The Noughties" Protest Movement in Russia: Genesis core [protest] social composition, it is primarily educated citizens with a high income and at the same time possessing a certain amount of free time. In addition, unlike the capital's "creative class", they are engaged in much closer to the real sector and the consumer spheres (small business: trade, household services, education, and engineering)" [17]. and Specificity", K. Podyachev, notes:"... As for the active

In the Internet activism evaluation, assessment of the users' involvement in a particular discussion plays a special role. As part of this study, we suggested that experts choose the most objective, in their view, formula for assessing the involvement of users. The first formula is a simple sum of involvement indicators- likes, reposts, and comments:

$$
\mathrm{ER}=[\text { likes }+ \text { reposts }+ \text { comments }],
$$

Where ER - involvement index.

The second, complicated formula illustrates the dependence of the indicators sum on the potential message audience:

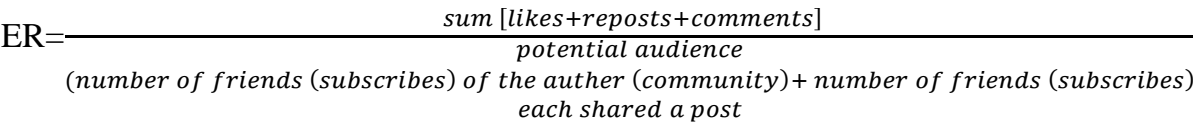

The overwhelming majority of experts $-75 \%$ - felt that the second formula, which takes into account the information audience, is objective. The possibilities of automatic social media analysis systems make it possible to use both formulas.

As the study results shows, Facebook is the best platform for organizing political campaigns (Table 5). The effectiveness of this site is due to a number of features, including regional ones:

- Regional and federal media journalists registered on Facebook and use social networks to find information

\footnotetext{
*Corresponding author: klyuyev@yandex.ru
} 
- Political actors' presence on Facebook directly influence the adoption of socially significant political decisions.

Table 5. Rating of the most effective sites for the Internet campaigns organization.

\begin{tabular}{|c|c|}
\hline Social network & Number \\
\hline Facebook & 9 \\
\hline $\begin{array}{c}\text { To conduct an effective political campaign, it is necessary to } \\
\text { use all available social networks }\end{array}$ & 7 \\
\hline Vkontakte & 3 \\
\hline Odnoklassniki & 1 \\
\hline Instagram & 1 \\
\hline Twitter & 0 \\
\hline Livejournal & 0 \\
\hline Forums (including thematic) & 0 \\
\hline
\end{tabular}

In addition, a significant number of experts believe that an effective campaign requires the use of all possible sites. Nevertheless, the type of some campaigns determines preferences for individual social networks: if Internet activists organize a campaign to create a bone marrow donors bank, then it is unlikely that they will succeed using, for example, a fairly "age-old" audience of "Odnoklassniki". On the contrary, they would have achieved greater success with a younger Vkontakte audience. Another example is the coverage of protests in Russia against the "Platon" organization, collection system for heavy vehicles moving along federal routes. Informing and mobilizing citizens would hardly have been possible with the use of the typically "female" Instagram, but reached its target audience in "Vkontakte".

\section{Conclusion}

When organizing an effective campaign, the organizers must take into account certain factors - environmental factors (the level of social networks penetration, the degree of media technology development, the state of the political conjuncture, the level of mass media development, the state of the political culture of society, the public request to solve a specific problem); and content factors (virality ("emotionality") of information, visuality). Besides two groups mentioned above, organizational factors (speakers' authority, group of initiators cohesion and the organization of their actions, the availability of the necessary resources for the campaign by the initiators) should be also in the focus of campaign organizers. In the course of the study, we managed to identify the most influential factors.

The question of the Internet campaigns independence in achieving socio-political goals remains open. The interviewed experts are inclined to believe that at the moment, Internet activism is a part of real campaigns and actions, but this situation can be radically broken with the development of electronic voting systems and the development of Internet tools for achieving socially significant goals (such as the "Russian Public initiative").

We can conclude that despite Internet audience growth and attempts to include users in public and political activities, the Russian population does not yet perceive the Internet as a platform for achieving meaningful social changes, or it happens unconsciously, for example, in spontaneous discussions of emerging problems. Thus, social media, while playing a significant role in the organization of civil activists' communication, so far remain only as one of the tool for achieving social and political goals.

The results of the expert survey and the analysis of available data on the factors influencing the Internet campaigns success make it possible to conclude that the most important circumstances that can have a significant impact on the success of the campaign are virality or visuality, and the authority of the speakers. Thus, less significant are, for example, the state of the political conjuncture or even the necessary resources availability for the campaign organizers. The analysis of this information allows Internet activists correctly focus their efforts and prioritize their activities, as well as directly implement the campaign by taking into account all the factors.

\section{References}

1. P. Barberá, T. Wang, PLoS ONE 10(11), (2015)

2. J. Blakley, Social Media and the end of gender. Retrieved from: https://www.ted.com/talks/johanna_blakley_social_media_and_the_end_of_gender

3. M. Diani, Communication and Society 3, 386-401 (2000)

4. F. Edwards, P. Howard, M. Joyce, Digital activism \& Non violent conflict. Digital Activism Research Project (Washington university, Seatlle, 2013)

5. D. R. Fisher, M. Boekkooi, Communication \& Society 13, 193-208 (2010)

6. M. Gerini, J. Stoyano, Proceedings of the 24th International Conference on World Wide Web (May 18-22, Florence, Italy, 2015)

7. A. Giddens, Modernity and Self-Identity: Self and Society in the Late Modern Age (Polity Press, Cambridge, UK, 1991)

8. M. Gladwell, New York, N.Y.: 1925 86(362),139-154 $\cdot(2011)$

9. Interest in politics: monitoring, Retrieved from: http://fom.ru/Politika/12680 
10. E. Izmestieva, Deep feelings: study results on the relationship between emotions and virality of Internet, Greenhouse of social technologies (2015). Retrieved from: https://te-st.ru/2015/07/09/deep-feelings

11. A. Kavada, Communication and Society 12, 817-839 (2009)

12. E. Khetagurova, Democracy Proponents missed the primaries turnout. Retrieved from: https://life.ru/t... na_praimieriz

13. B. Klandermans, The Blackwell Companion to Social Movements (Blackwell, Oxford, 2004)

14. D. Kuznetsov, Sofa troops are recognized as an important part of the protest. Retrieved from: https://nplus1.ru/news/2015/12/08/slackers-strikeback

15. Mercea, D.: Towards a Conceptualization of Casual Protest Participation: Parsing a Case from the Save Roşia Montană Campaign. East European Politics and Societies and Cultures. 28 (2), 386-410 (2014)

16. Olenitskaya, E.S.: Tools for social media analyzing. In VII All-Russian Political Scientists Congress Political science before and modern politics challenges, p. 1122. RAPN, Moscow (2015)

17. K. Podyachev, "The Noughties" Protest Movement in Russia: Genesis and Specificity". Retrieved from: http://www.perspektivy.info/book/protestnoje_dvizhenije_v_rossii_nulevyh_genezis_i_specifika_2013-03-19.htm (date: 26.05.2016)

18. P. Sedokov, Lords of the likes: how Sidorin Lab creates an Internet reputation. Retrieved from: http://www.forbes.ru/svoi-biznes/startapy/313553poveliteli-laikov-kak-sidorin-lab-sozdaet-reputatsiyuv-internete

19. J. Snow, L. A. Zurcher, S. Ekland-Olson, American Sociological Review 45, 787-801 (1980)

20. Z. Tufekci, Online social change: easy to organize, hard to win, Retrieved from: https://www.ted.com/talks/zeynep_tufekci_how_the_i nternet_has_made_social_change_easy_to_organize_hard_to_win

21. J. Van Stekelenburg, B. Klandermans, Handbook of Social Movements across Disciplines (Springer, New York, 2010) 